\title{
Current fishing practices may induce low risk of sperm limitation in female swimming crab Portunus trituberculatus in the East China Sea
}

\author{
Fujun Xuan ${ }^{1, *}$, Weibing Guan ${ }^{2, *}$, Chengman Bao $^{2}$, Fenghua Tang ${ }^{3}$, Boping Tang ${ }^{1}$, \\ Chunlin Zhou ${ }^{1}$ \\ ${ }^{1}$ Jiangsu Provincial Key Laboratory of Coastal Wetland Bioresources and Environmental Protection, \\ Yancheng Teachers University, Yancheng, Jiangsu 224051, PR China \\ ${ }^{2}$ Key Laboratory of Shanghai Education Commission for Oceanic Fisheries Resources Exploitation, \\ Shanghai Fisheries University, Shanghai 200090, PR China \\ ${ }^{3}$ Key Laboratory of East China Sea \& Oceanic Fishery Resources Exploitation and Utilization, Ministry of Agriculture, \\ East China Sea Fisheries Research Institute, Chinese Academy of Fishery Sciences, Shanghai 200090, PR China
}

\begin{abstract}
Potential sperm limitation of the swimming crab Portunus trituberculatus was examined during the reproductive season from September 2006 to April 2007 in the East China Sea. We documented developmental variations between the spermatheca and ovary and distinguished these into 5 stages. We counted the number of stored sperm in paired spermathecae and found that more than $50 \%$ of sperm initially received during mating disappeared as the sperm plug degenerated; around $1.70 \times 10^{8}$ were used for final fertilization, and there was significant correlation between the final number of stored sperm and female carapace width. Lastly, using knowledge of the reproductive characteristics of $P$. trituberculatus, we calculated potential sperm:egg ratios of 221:1 or 153:1 for the first brood, and 55:1 or 38:1 for lifetime broods - either from the perspective of a fishery resource assessment or from the perspective of seed production. From comparison to sperm:egg ratios of Callinectes sapidus (for lifetime broods this ranges from 10:1 to 42:1), we can infer that female $P$. trituberculatus in the East China Sea may be at low risk of sperm limitation under current fishing practices. This may be the result of greater fishing mortality of females, causing an increase in the operational sex ratio. The present study improves our knowledge of sperm limitation in brachyurans as fishing management in China is non-selective, which differs from other exploited decapod crustacean species around the world.
\end{abstract}

KEY WORDS: Portunus trituberculatus $\cdot$ Sperm limitation $\cdot$ Non-selective fishing $\cdot$ East China Sea Resale or republication not permitted without written consent of the publisher

\section{INTRODUCTION}

Sperm limitation occurs when the number of sperm received by females is insufficient to fertilize the total number of potential eggs. In species with direct sperm transfer, sperm limitation may arise naturally from spatial or temporal variability in the population demographic structure (Pitnick 1993), while anthropogenic effects caused by selective harvesting may aggravate any underlying natural causes. For example, an increasing number of studies report the existence or possibility of various degrees of sperm limi- tation under sex- (male only) and/or size-selective (size limit) management for several exploited decapod crustacean species, including Chionoecetes opilio (Sainte-Marie \& Lovrich 1994, Sainte-Marie et al. 2002), Cancer magister (Hankin et al. 1997), Callinectes sapidus (Kendall et al. 2001, Hines et al. 2003, Carver et al. 2005), Pseudocarcinus gigas (Gardner \& Williams 2002), Paralithodes brevipes (Sato et al. 2006, 2007) and Birgus latro (Sato et al. 2010). Such cases of selective fishing can change the population structure by reducing the average size and density of males, as well as reducing the operational sex ratio 
(OSR) of males to females (Hines et al. 2003, Carver et al. 2005, Sato \& Goshima 2006). Therefore, sperm limitation can contribute to the structure of mating systems (Wedell et al. 2002), and knowledge of the process of sperm limitation may be beneficial to conservation and management efforts (Conover \& Munch 2002, Sainte-Marie et al. 2002).

A critical step in estimating the risk of sperm limitation in brachyurans is to determine whether the final quantities of sperm stored in female spermathecae are 'sufficient' to meet the possible minimum ratio of spermatozoon to oocyte for fertilization, to ensure reproductive success. However, there are relatively few reports concerning these important reproductive parameters. In Chionoecetes species, ratios for high fertilization success are reported to range from 'several' sperm per egg (Adams \& Paul 1983) to actual expenditure of an estimated 70 stored sperm per egg for the first clutch extruded (SainteMarie \& Lovrich 1994); females failed to extrude any eggs when the sperm:egg ratio was below 7:1 (SainteMarie \& Lovrich 1994). In comparison, sperm:egg ratios in C. sapidus were estimated at 100:1 to 400:1 for the first brood, and only 20:1 to 30:1 for maximum lifetime broods over the 2 possible reproductive seasons, suggesting that approximately $67 \times 10^{6}$ sperm are used per brood of $3 \times 10^{6}$ eggs (Hines et al. 2003). This calculation may overestimate sperm usage in $C$. sapidus, because it neglects any attrition of sperm that occurs during the periods of prolonged storage following mating as spermathecal weight declines and ovarian volume enlarges (Wolcott et al. 2005). Indeed, nearly $50 \%$ of sperm are thought to be lost prior to brood production (Wolcott et al. 2005). Moreover, little is known of these processes for crustaceans other than C. sapidus.

The swimming crab Portunus trituberculatus (Miers 1976) occurs almost exclusively along the coast of China, and is the most heavily fished brachyuran in the world with annual landings of 300000 tonnes (FAO 2006). Due to overfishing, destruction of coastal spawning and nursery grounds and marine pollution, the landing of the crab has declined in the East China Sea region since the 1990s (Yu et al. 2003, 2004, 2006). However, there have been few serious attempts to manage this resource based on scientific evidence, except for certain obvious recommendations such as 'protecting spawners during the spring, maintaining spatial nursery habitats in the summer, and conducting fishing activities in winter', which were established the by Zhoushan local government in Zhejiang Province (Zhaung \& Deng 1999, Yu et al. 2003). Fishing activities in China are non-selective, meaning that both sexes are harvested and there is no size limit on caught animals (though consumers have a preference for females - especially those with developed ovaries - and this makes them more valuable at market) (Yu et al. 2003). Fishing has led to considerable changes in $P$. trituberculatus population structure in the East China Sea. Mean crab carapace width (CW) and body weight declined from $163.1 \mathrm{~mm}$ and $259.3 \mathrm{~g}$ in a coastal fishery survey conducted in 1982 and 1983 (Song et al. 1988) to $149.5 \mathrm{~mm}$ and $217.5 \mathrm{~g}$ in a survey conducted between 1997 and 2000 (Zhen et al. 2003).

Portunus trituberculatus is a typical short-generation species with a life-span of no more than 3 yr (Dai et al. 1977, Xue et al. 1997). Laboratory observations have shown that male crabs reach sexual maturity at the $9^{\text {th }}$ to $11^{\text {th }}$ postlarval instar, and can mate with soft-females who become receptive after their $10^{\text {th }}$ or $11^{\text {th }}$ molt. Males do not undergo a terminal molt at maturity, as crabs during the $9^{\text {th }}$ instar can continue to molt after mating within the same reproductive season, while females stop molting to develop ovaries and prepare for their lifetime egg production (Sun et al. 1984). In our study area off the coast of Zhejiang Province (Fig. 1), the spawning stock CW ranges from 100 to $240 \mathrm{~mm}$ and the dominant group ranges from 130 to $180 \mathrm{~mm}$ (Song et al. 1988). Mating begins in July and extends through November (with peak mating occurring around October), while ovigerous females appear from April through June (Song et al. 1988, Xue et al. 1997). During 2005 and 2006, we studied annual changes of $P$. trituberculatus male and female reproductive systems using morphological and biological methods (Guan et al. 2009, Xuan et al. 2009). In the present study, we investigated the possibility of sperm limitation under nonselective fishing of $P$. trituberculatus during a reproductive season from September 2006 to April 2007 in the East China Sea. This study aims to deepen the knowledge of sperm limitation in the economically important decapod crustacean species worldwide, as there are no previous reports of this information available for $P$. trituberculatus. Furthermore, it remains unclear whether there is a risk of sperm limitation in female $P$. trituberculatus under non-selective fishing. Although the OSR of males to females may be unchanged or even have increased relative to prefishery times, the density of mature crabs may have declined to a point where females do not always encounter a mate during their limited receptive period (2 d after molt; authors' pers. obs.), or remaining males may be too small to fully inseminate females due to their low sperm reserve (sperm reserve of $P$. trituber- 


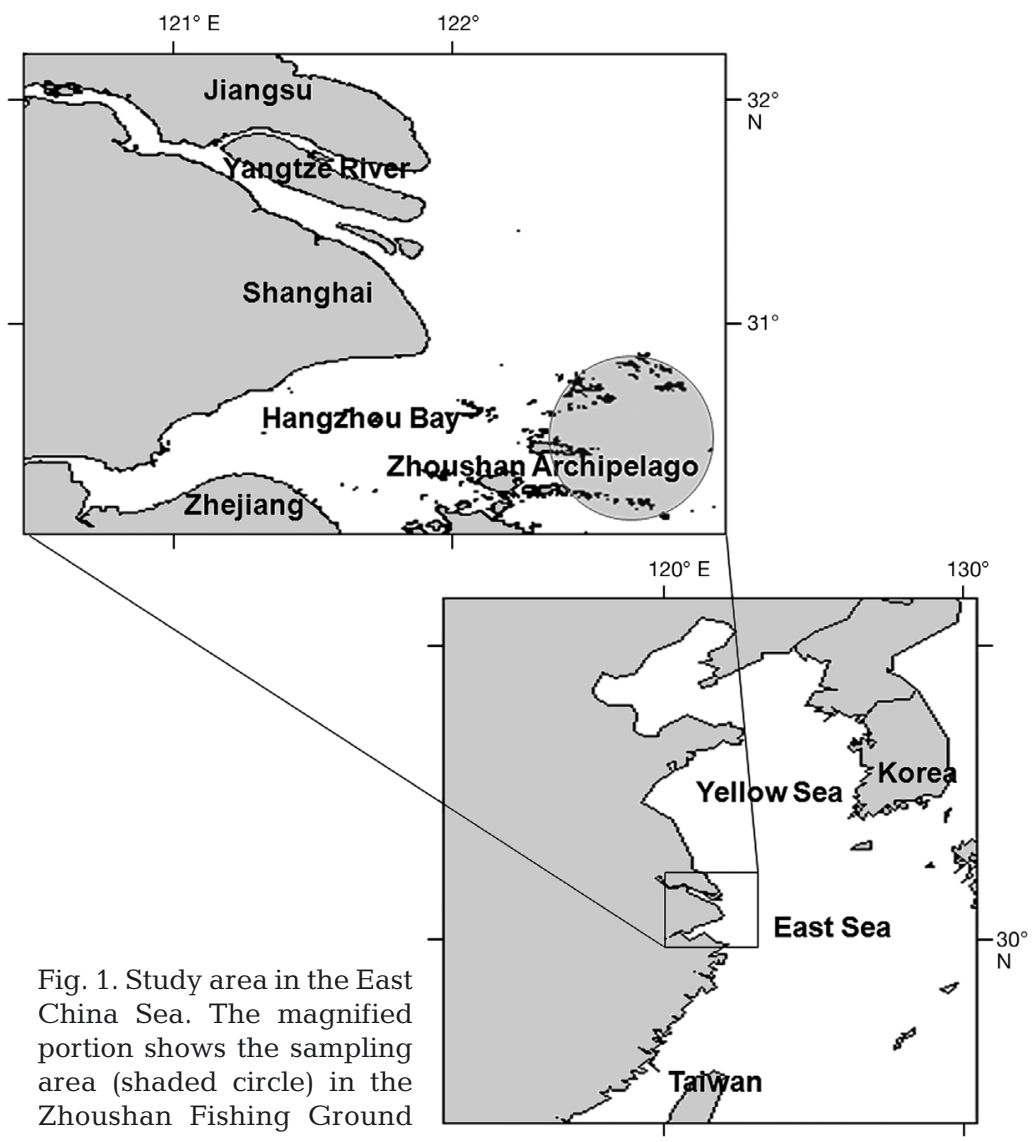

tomized) and were measured for CW (the distance between the $9^{\text {th }}$ lateral spine tips was determined with a caliper to the nearest $0.1 \mathrm{~mm}$ ) and body weight (total wet weight was determined with an electronic balance to the nearest $0.1 \mathrm{~g}$ ). In the study area, salinity ranged from 26 to 33 , and temperature ranged from 13 to $19^{\circ} \mathrm{C}$.

\section{Assessment of spermathecal and ovarian developmental stages}

Females were sacrificed by placing them in a freezer $\left(-20^{\circ} \mathrm{C}\right)$ for approximately $30 \mathrm{~min}$. The females were dissected, and spermathecal condition was recorded following the Xuan et al. (2009) scale: (I) contracted completely (before mating), in which the spermathecal wall was thick and the lumen contained merely some jelly-like matrix; (II) hard plug (just mated), in which the spermathecal wall was expanded and seminal fluid had formed a hard sperm plug; (III) partial plug (several weeks after mating), in which the sperm plug had largely degraded and the lumen contained liquid material and some disso-

culatus is positively correlated to male body size; Xuan et al. unpubl. data). To investigate the possibility of sperm limitation, we first assessed spermathecal and ovarian development, and counted sperm in the paired spermathecae. We then assessed what percentage of sperm was lost, and investigated the correlation between final sperm numbers and female carapace size. Lastly, we compared female sperm counts with previous reports, and assessed the current condition of female mating success from the aspect of sperm limitation in the East China Sea.

\section{MATERIALS AND METHODS}

The survey was carried out in the Zhoushan Fishing Ground of the East China Sea (30 to $31^{\circ} \mathrm{N}, 122$ to $123^{\circ} \mathrm{E}$ ), located in the east of Zhejiang Province (Fig. 1). A total of 34 pre-pubertal and 162 mature females (distinguished by differences in the abdominal shape; authors' pers. obs.) were randomly collected using local crab traps each month from September 2006 (close to the mating peaki Song et al. 1988) to April 2007 (before ovulation; Song et al. 1988). All crabs used were intact (i.e. no limbs autociated spermatophores; (IV) mostly resorbed (1 or more month after mating), in which the sperm plug had disappeared and the spermatophore wall had decomposed, while the lumen contained free sperm and some liquid material; and (V) resorbed (before ovulation), in which the spermathecal wall was very thin and flaccid, and only free sperm remained in preparation for impending ovulation and fertilization. After recording spermathecal condition, the spermathecae and ovaries were removed, separated, blotted and weighed to the nearest $1 \mathrm{mg}$. During this process, many spermathecae were excluded because spermathecae were susceptible to tearing when the ovary was separated from the spermatheca. Others were translucent and contained some liquid material, but were difficult to dissect due to poor development. As a result, we obtained a total of 69 intact paired spermathecae, 56 of which contained seminal fluid and spermatophores and/or sperm.

Ovaries were recorded to be at 1 of 5 stages (Wu et al. 2007): Stage I: threadlike and transparent, in which the ovaries were undeveloped; Stage II: bandlike and opalescent, in which the ovaries had just begun to develop; Stage III: band-like and yellowish, in which the volume of the ovaries had increased and 
ovocytes could be distinguished but not separated; Stage IV: reddish, with volume increasing sharply, in which ovocytes were easily recognized and separated; Stage V: reddish, with volume increased up to its largest level, in which the ovaries were fully developed and the ovocytes were extremely obvious, in preparation for ovulation. In addition, we also calculated the ovarian index values for the 196 individuals by dividing the wet ovarian weight by the body weight.

\section{Sperm count}

The sperm counting procedure was performed as described by Wolcott et al. (2005). Briefly, if the sperm plugs were hard, the spermathecal walls were removed and the contents were minced to $<2 \mathrm{~mm}$ pieces with a scalpel or razor blade before being poured into a Dounce homogenizer; however, if the seminal fluid had been resorbed, the contents were washed directly into the homogenizer with 30 psu artificial seawater. The spermathecal contents were then homogenized until all particles were small enough to pass around the pestle into the supernatant. Next, samples were filtered through a $35 \mu \mathrm{m}$ Nitex cloth supported by a funnel into a graduated cylinder. During this process, the spermathecal wall and pestle of the homogenizer were checked for any residual spermatophore and/or sperm, and steps were repeated until the spermatheca and homogenizer were free of sperm. The filtrates from different individuals were diluted to various volumes (400 to $8000 \mathrm{ml}$ ) and stained with $1 \%$ gentian violet to facilitate sperm counting. A sub-sample was then pipetted onto a Petroff-Hauser spermacytometer that was used to enumerate sperm at $1000 \times$ magnification. Lastly, 3 replicate counts were averaged and used to extrapolate the total number of sperm. In total, we examined sperm from 56 paired spermathecae.

\section{Potential sperm:egg ratio}

The number of sperm finally stored by each female was estimated from the sperm counts (spermathecal Stages III to $\mathrm{V}, \mathrm{n}=46$ ), while corresponding egg fecundity $(F)$ was estimated from the regression with female bodyweight $(\mathrm{W})$ as follows: $\mathrm{F}=2034 \mathrm{~W}^{1.099}$ (Song et al. 1988); $F=6800 W^{0.9413}$ (Fu et al. 2006). Both formulae are based on field samplings in our study area. The former equation is used in fishery resource assessments and is thought to be more repre- sentative of fecundity in the natural population. The latter equation is derived from females selected for seed production which may have larger bodies and greater fecundity-at-size than average. In addition, the values of $\mathrm{F}$ from both formulae merely correspond to the egg number of the first brood. Therefore, considering the fact that the quantity of the second ovulation of Portunus trituberculatus is no more than one third of the first, and that few individuals spawn a third time during the reproductive season (Song et al. 1988), we can assume that total F of $P$. trituberculatus in a reproductive season is identical to 2 times that of the female's first brood. Lifetime F may be about 4 times this value, since the lifespan of $P$. trituberculatus is no more than $3 \mathrm{yr}$, and each animal typically experiences only 2 reproductive seasons (Dai et al. 1977, Xue et al. 1997).

\section{Statistical analyses}

All data were log-transformed during tests of significance to meet assumptions of normality and homogeneity of variance. Seasonal and developmental differences in paired spermathecal weights, sperm abundance and ovarian index values were compared by general linear model using SPSS software. Month, ovary stage or spermathecal stage was entered as a fixed factor, while female CW was always used as a covariate (since female sizefecundity relationship might influence male seminal material allocation; Jivoff et al. 2007, Sainte-Marie 2007) in the factorial analyses. The Bonferonni test was used to distinguish significant differences amongst the multi-level variables, while Student's $t$-tests were used to compare data between 2 groups. In addition, linear regressions between female CW and the final amount of stored sperm, and between female CW and potential sperm:egg ratio were also examined.

\section{RESULTS}

\section{Spermathecal and ovarian conditions}

Seasonal changes in the representation of crabs by spermatheca or ovary condition are presented in Table 1. Close to the mating peak (September), most of the spermathecae were contracted (Stage I) or otherwise poorly developed, probably in preparation for subsequent copulation. In October and November, the hard sperm plug appeared (which indicated mating activity had just occurred), the spermathecae 
Table 1. Portunus trituberculatus. Spermathecal and ovarian conditions of $P$. trituberculatus in the East China Sea during a reproductive season from September 2006 to April 2007. The dash (-) in the 'Condition of spermathecae' column indicates that the spermathecae had poor development and failed to meet the scale in accordance with Xuan et al. (2009); the different superscript letters in the 'Ovary index' column indicate a significant difference between means at the 0.05 level. For definitions of the 'Condition of spermathecae' and 'Ovary development stages', see 'Materials and methods: assessment of spermathecal and ovarian developmental stages'

\begin{tabular}{|c|c|c|c|c|c|c|}
\hline Month & $\begin{array}{l}\text { Carapace width (mm) } \\
\text { (Median value) }\end{array}$ & $\begin{array}{c}\text { Number } \\
\text { (Prepubertal female) }\end{array}$ & $\begin{array}{l}\text { Condition of } \\
\text { spermathecae }\end{array}$ & $\begin{array}{c}\text { Proportion at } \\
\text { different stages }\end{array}$ & $\begin{array}{c}\text { Ovary } \\
\text { development }\end{array}$ & Ovary index \\
\hline September & $\begin{array}{l}80-190 \\
(132.8)\end{array}$ & $\begin{array}{c}23 \\
(23)\end{array}$ & $\overline{\mathrm{I}}$ & $\begin{array}{l}13.1 \\
86.9\end{array}$ & $\begin{array}{l}\text { I } \\
\text { I }\end{array}$ & $0.55 \pm 0.75^{a}$ \\
\hline October & $\begin{array}{c}120-200 \\
(149.5)\end{array}$ & $\begin{array}{c}23 \\
(11)\end{array}$ & $\begin{array}{c}- \\
\text { I } \\
\text { II } \\
\text { III }\end{array}$ & $\begin{array}{l}21.7 \\
26.1 \\
30.4 \\
21.7\end{array}$ & $\begin{array}{c}\text { I } \\
\text { I } \\
\text { II-III } \\
\text { III }\end{array}$ & $1.50 \pm 0.75^{\mathrm{a}}$ \\
\hline November & $\begin{array}{c}120-230 \\
(151.3)\end{array}$ & $\begin{array}{l}36 \\
(0)\end{array}$ & $\begin{array}{c}\text { II } \\
\text { III } \\
\text { IV } \\
\text { V }\end{array}$ & $\begin{array}{c}44.5 \\
5.6 \\
44.5 \\
5.6\end{array}$ & $\begin{array}{c}\text { II-III } \\
\text { III } \\
\text { III } \\
\text { III }\end{array}$ & $2.50 \pm 0.75^{\mathrm{a}}$ \\
\hline December & $\begin{array}{c}130-210 \\
(152.1)\end{array}$ & $\begin{array}{l}28 \\
(0)\end{array}$ & $\begin{array}{l}\text { III } \\
\text { IV } \\
\text { V }\end{array}$ & $\begin{array}{l}10.7 \\
60.7 \\
28.6\end{array}$ & $\begin{array}{c}\text { III } \\
\text { III-IV } \\
\text { IV-V }\end{array}$ & $7.54 \pm 0.69^{b}$ \\
\hline Jan-Feb & $\begin{array}{c}120-200 \\
(151.2)\end{array}$ & $\begin{array}{l}42 \\
(0)\end{array}$ & $\begin{array}{l}\text { IV } \\
\text { V }\end{array}$ & $\begin{array}{l}47.6 \\
52.4\end{array}$ & $\begin{array}{l}\text { IV-V } \\
\text { IV-V }\end{array}$ & $9.25 \pm 0.54^{\mathrm{c}}$ \\
\hline Mar-Apr & $\begin{array}{c}130-230 \\
(153.2)\end{array}$ & $\begin{array}{l}44 \\
(0)\end{array}$ & $\begin{array}{l}\text { IV } \\
\text { V }\end{array}$ & $\begin{array}{l}27.3 \\
72.7\end{array}$ & $\begin{array}{l}\text { IV-V } \\
\text { IV-V }\end{array}$ & $10.12 \pm 0.43$ \\
\hline
\end{tabular}

walls were expanded and the spermathecae had increased in volume (Stage II). Only 1 intact sperm plug was contained in each spermatheca. As sampling time progressed, the sperm plug began to degenerate (Stage III). By December, the sperm plug had almost disappeared and the spermathecae had become small and flaccid (Stage IV or V). Spermathecal weight changed significantly through these 5 spermathecal stages (ANCOVA with CW as a covariate: $F_{4,63}=$ 33.887, $\mathrm{p}<0.001$ ) and after a distinct increase (Stages I to II; Bonferonni test, $\mathrm{p}<0.001$ ), the mean adjusted weight per spermathecae pair sharply declined from $1.534 \mathrm{~g}$ following copulation (Stage II) to around $0.3 \mathrm{~g}$ per pair in Stages III to V (Bonferonni pairwise comparisons: $p>0.05$; Fig. 2 ). At the same time, the ovary developed and the corresponding ovarian index advanced with months (ANCOVA with $\mathrm{CW}$ as a covariate: $\left.F_{5,189}=34.536, \mathrm{p}<0.001\right)$, from 0.55 in September (ovarian Stage I before mating) to 10.12 during March-April (Stage IV or V before ovulation; Table 1). Moreover, the weights of the spermathecae were related to $\mathrm{CW}\left(F_{1,63}=24.553, \mathrm{p}<0.001\right)$ but the ovarian index was not $\left(F_{1,189}=0.086, \mathrm{p}=0.782\right)$.

\section{Number of stored sperm in the female}

The average number of sperm in each female after copulation varied significantly between spermathe- cal Stages II to V (ANCOVA with CW as a covariate: $F_{3,51}=13.546, \mathrm{p}<0.001$; Fig. 3). Following mating (Stage II), the paired spermathecae contained a hard sperm plug and the mean number of sperm was 7.32 $\times 10^{8}$, but as the sperm plug degraded (Stage III), more than $50 \%$ of this sperm disappeared and sperm number dropped to $1.74 \times 10^{8}$ (Bonferonni test: $\mathrm{p}<$

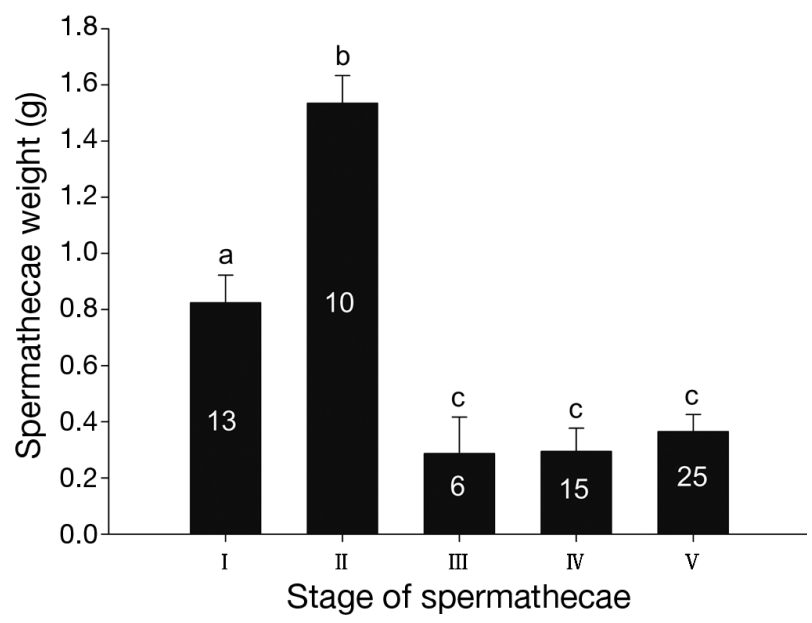

Fig. 2. Portunus trituberculatus. Average weight of paired spermathecae for a given spermathecal stage prior to production of the first brood. Numbers in columns are re-sample sizes, and columns sharing the same letter are not significantly different. The mean values of spermathecal weight were adjusted to a common carapace width of $151.3 \mathrm{~mm}$ by ANCOVA. Error bars are standard errors of means 


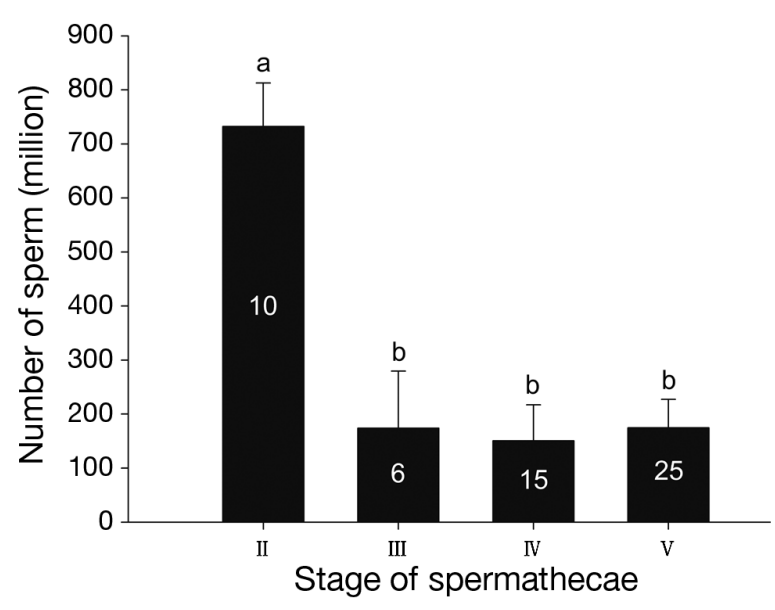

Fig. 3. Portunus trituberculatus. Average sperm number in paired spermathecae for a given spermathecal stage prior to production of the first brood. Numbers in columns are resample sizes, and columns sharing the same letter are not significantly different. The mean values of sperm number were adjusted to a common carapace width of $156.2 \mathrm{~mm}$ by

ANCOVA. Error bars are standard errors of means

0.001). After that, sperm numbers were stable at around $1.70 \times 10^{8}$ prior to the production of the first brood (Stages IV and V; Bonferonni test: $\mathrm{p}>0.05$ ). We also determined that the number of sperm received by each female was influenced markedly by female CW $\left(F_{1,51}=9.086, \mathrm{p}=0.004\right)$.

To better understand the relationship between female size and the final quantity of sperm stored in the spermathecae, we excluded data from spermathecal Stage II crabs and prepared a regression between CW and the remaining sperm counts (Fig. 4). The resulting regression had a significant positive slope $\left(F_{1,44}=27.327, \mathrm{p}<0.001\right)$ although this regression only explained $39 \%$ of the variance (Fig. 4 ).

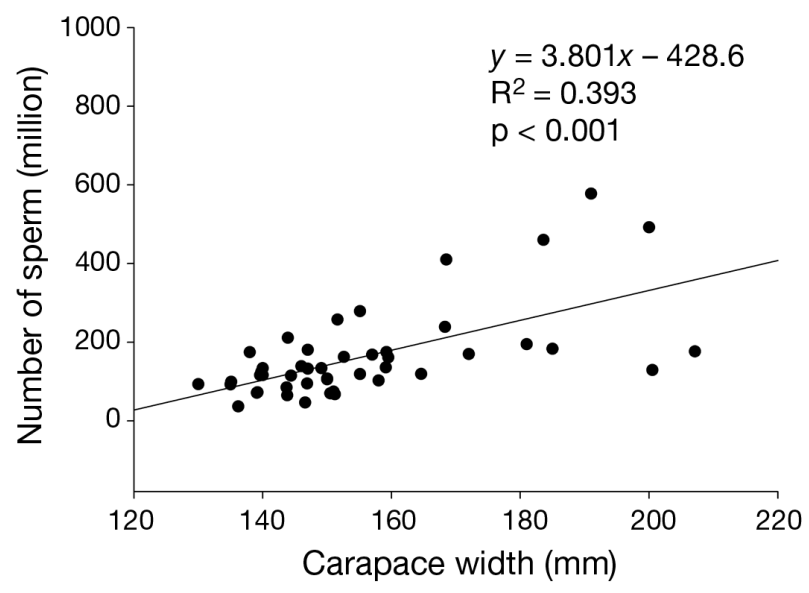

Fig. 4. Portunus trituberculatus. Relationship between carapace width and sperm number in paired spermathecae of spermathecal Stages III to V

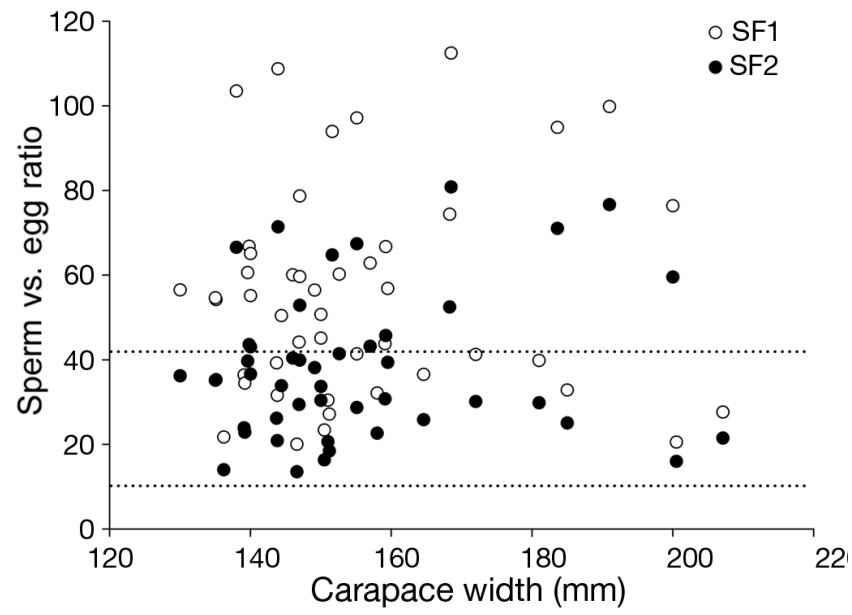

Fig. 5. Portunus trituberculatus. Scatterplots of potential sperm:egg ratios of lifetime egg production based on sizefecundity regressions (SF1 from Song et al. 1988; SF2 from Fu et al. 2006). The area delineated by 2 parallel dashed lines represents the estimated sperm:egg ratios ranging from 10 to 42 for blue crabs, taking into account attrition caused by sperm storage (Hines et al. 2003, Wolcott et al. 2005)

\section{Analysis of the potential ratio of sperm versus egg}

The 2 different predictive equations for fecundityat-size resulted in divergent estimates of sperm to egg ratios (Figs. 5). The Song et al. (1988) equation calculated the sperm:egg ratio to range from $80: 1$ to 449:1, with an average of 221:1 for the first brood; whereas using the Fu et al. (2006) equation the ratio ranged from 53:1 to 306:1 (mean of 153:1). So the ratios in the Song et al. (1988) study were significantly higher $(t=3.822, \mathrm{p}<0.001)$ if we discounted any temporal difference. In addition, considering the total number of ovulations in a reproductive season we could further postulate that the average ratio might be reduced to $110: 1$ or $77: 1$ (identical to one and a half of the first brood value), while the lifetime ratio might be $55: 1$ or $38: 1$ (one-quarter of the first brood value). Meanwhile, we also found that the potential lifetime sperm:egg ratios were independent of female CW (Fig. 5) based on either the Song et al. (1988) equation $\left(F_{1,44}=0.24, \mathrm{p}=0.876\right)$ or the $\mathrm{Fu}$ et al. (2006) equation $\left(F_{1,44}=0.876, \mathrm{p}=0.354\right)$.

\section{DISCUSSION}

Predictable changes in the female spermathecae of Portunus trituberculatus and their contents occur between copulation and prior to brood production (Fig. 2, Table 1). In early September, most spermathecae were tightly contracted in preparation for mat- 
ing (spermatheca in Stage I). After mating, the hardened sperm plug, a reliable indicator of mating in decapods (Oh \& Hankin 2004, McLay \& López Greco 2011), appeared in both spermathecae (Stage II). Thus, our observations implied that the mating peak in the East China Sea occurred during October and November (Xuan et al. 2009). Up to December, the sperm plug largely degenerated (Stage III), and in some crabs even disappeared, while the spermathecae eventually became small and flaccid (Stages IV and V). In this process, the ovaries developed. As the weight of the spermathecae declined following copulation, the ovarian index increased considerably. Thus, this alternation between ovary and spermathecae development may be evolutionarily significant as has been found in other brachyurans (Sainte-Marie 1993, Jensen et al. 1996, Hines et al. 2003, Wolcott et al. 2005, Sainte-Marie 2007). Most importantly, the correlation between ovarian stage and spermathecal stage may allow the estimation of time elapsed since mating for wild females.

More than $50 \%$ of sperm received at mating disappeared before first brood production. The decline in quantity of the stored sperm mainly occurred in spermathecal Stage III, and accompanied the degeneration of the sperm plug. Therefore, the process of sperm loss may be related to the degradation of the sperm plug, especially as after this stage the number of sperm remains at a relatively stable level (Fig. 3). In addition, the final quantity of stored sperm was correlated significantly with female CW (Fig. 4), which was suggestive of female size-dependent sperm allocation by males. Thus, the crab may also perform size-assortative mating as has been observed for Callinectes sapidus (Kendall et al. 2002) and Chionoecetes opilio (Sainte-Marie \& Hazel 1992); alternatively, males may allocate sperm strategically based on socio-sexual context and/or female characteristics, as stated in the previous comment (Jivoff et al. 2007, Sainte-Marie 2007). Combined with the fact that larger females are also capable of producing larger broods (Song et al. 1988, Fu et al. 2006), the correlation between spermathecal sperm storage capacity and female CW (i.e. fecundity) fits the principle that selection should favor individuals of both genders pairing with as large a mate as possible (Carver et al. 2005).

Sperm is considered limiting if a female receives an insufficient amount to fertilize her full reproductive potential (Hines et al. 2003), but the amount considered to be sufficient is poorly understood. In the East China Sea, the final number of stored sperm in Portunus trituberculatus females is approximately
$1.70 \times 10^{8}$, which is far less than observed with Callinectes sapidus (belonging to the Portunidae), which receives about $9.3 \times 10^{8}$ sperm, even after mating with a recently-mated male (Kendall et al. 2002). However, considering the almost $50 \%$ sperm attrition prior to ovulation (Wolcott et al. 2005), the fact that most of a crab's reproductive output is from the first few broods, and that the percentage of embryos developing normally and brood volume are decreased with successive broods (Darnell et al. 2009), the sperm:egg ratio of $C$. sapidus would be estimated to be 50:1 to 200:1 for the first brood. That estimate would be even less than 10:1 to 42:1 for the last few broods due to its ability to produce multiple broods over 2 reproductive seasons ( 6 to 18 broods; Hines et al. 2003, Wolcott et al. 2005). Thus, P. trituberculatus may have similar or even higher sperm:egg ratios estimated using either size-fecundity relationship for its limited 4 lifetime broods (221:1 or 153:1 for the first brood and 55:1 or 38:1 for lifetime broods, respectively, Song et al. 1988, Fu et al. 2006). Moreover, the higher estimates (221:1 and 55:1) of sperm: egg ratios for $P$. trituberculatus are likely to be more realistic, as they represent only field conditions (Song et al. 1988). Finally, we also created scatter plots of potential sperm:egg ratios versus CW for $P$. trituberculatus lifetime egg production from the 2 aspects mentioned above to detect individual conditions in the East China Sea (Song et al. 1988, Fu et al. 2006; Fig. 5) and found that all dots fell into or above the delineated ratios area for $C$. sapidus, ranging from 10 to 42 (Hines et al. 2003, Wolcott et al. 2005). Therefore, although we have not determined empirically the minimum amount of sperm needed for complete fertilization of $P$. trituberculatus, it seems that the potential for sperm limitation is low for this crab in the East China Sea under current fishing pressure, by comparison to the C. sapidus sperm:egg ratio (Hines et al. 2003).

So why is the Portunus trituberculatus in the East China Sea seemingly not at risk of sperm limitation? There are no obvious answers or references to solve this question since $P$. trituberculatus fishing in China is non-selective, which differs from other exploited decapod fisheries such as Chionoecetes opilio (SainteMarie et al. 2002), Callinectes sapidus (Kendall et al. 2001, Carver et al. 2005), Pseudocarcinus gigas (Gardner \& Williams 2002), Paralithodes brevipes (Sato et al. 2007) and Birgus latro (Sato et al. 2010), which are generally male-only and/or size-limited. However, since the 1990s, the spawning stock of $P$. trituberculatus has been under continual, intensive over-fishing (Yu et al. 2003, 2004), and individual 
crab size and body weight have declined noticeably (Song et al.1988, Zhen et al. 2003). Our monthly samplings indicate that females in the East China Sea may have only 1 mating opportunity during the mating season, as we did not observe 2 or more sperm plugs in one spermatheca, as was previously found in C. sapidus (Jivoff 1997). Therefore, we can further speculate that current fishing activities may reduce the chances of sperm limitation by harvesting both male and female crabs, and removing more females, both of which would decrease the density of the stock but raise the male bias of OSR.

In conclusion, our research strongly suggests that female Portunus trituberculatus in the East China Sea may be at low risk of sperm limitation under current non-selective fishing pressure. To continue our work, other corresponding field investigations, such as quantifying the current levels of egg production relative to the unfished state, and laboratory experiments (e.g. brood production and embryonic development), will be performed to study sperm limitation in $P$. trituberculatus, similar to that which has been conducted in other decapod crustacean species. These investigations will aim to formulate an appropriate management system to protect this valuable marine resource in the East China Sea.

Acknowledgements. We thank G. Zhang for sperm counting. We thank Dr. D. Wolcott, B. Sainte-Marie, C. Gardner, T. Sato and P. Jivoff for providing us the relative papers, and other anonymous reviewers for valuable comments. This study was supported by grants from the Natural Science Fund for Colleges and Universities in Jiangsu Province (No. 13KJB180027), Yancheng City Agricultural Science and Technology Innovation Fund Project and Yancheng Teachers University Foundations (Nos. 2YSYJB0120 and JKLBS2012028) to F.X.

\section{LITERATURE CITED}

Adams AE, Paul AJ (1983) Male parent size, sperm storage and egg production in the crab Chionoecetes bairdi (Decapoda, Majidae). Int J Invertebr Reprod 6:181-187

Carver AM, Wolcott TG, Wolcott DL, Hines AH (2005) Unnatural selection: effects of a male-focused sizeselective fishery on reproductive potential of a blue crab population. J Exp Mar Biol Ecol 319:29-41

- Conover DO, Munch SB (2002) Sustaining fisheries yields over evolutionary time scales. Science 297:94-96

Dai AY, Feng ZQ, Song YZ, Huang ZX, Wu HC (1977) Preliminary investigation of the fishery biology of the blue crab Portunus trituberculatus. Chin J Zool 12:30-33

- Darnell MZ, Rittschof D, Darnell KM, McDowell RE (2009) Lifetime reproductive potential of female blue crabs Callinectes sapidus in North Carolina, USA. Mar Ecol Prog Ser 394:153-163

Gardner C, Williams H (2002) Maturation in the male giant crab, Pseudocarcinus gigas and the potential for sperm limitation in the Tasmanian fishery. Aust J Mar Freshw Res 53:661-667

Guan WB, Xuan FJ, Chen HH, Dai XJ, Zhu JF (2009) Spermatogenesis and spermatophore formation of the swimming crab (Portunus trituberculatus Miers, 1876) in East China Sea. J Fish Sci China 16:173-179

FAO (2006) FAO fisheries global information system. Available at www.fao.org/fishery/species/2630/en

Fu RB, Wu XG, Cheng YX, Wang C, Chen S, Luo H (2006) A comparative study on egg production between pondreared and wild Portunus trituberculatus in Zhoushan Sea area. J Zhejiang Ocean Univ 25:138-142

Hankin DG, Butler TH, Wild PW, Xue QL (1997) Does intense fishing on males impair mating success of female Dungeness crab? Can J Fish Aquat Sci 54:655-669

Hines AH, Jivoff PR, Bushmann PJ, VanMontfrans J, Wolcott DL, Wolcott TG (2003) Evidence for sperm limitation in female blue crabs (Callinectes sapidus). Bull Mar Sci 72: 287-310

Jensen PC, Orensanz JM, Armstrong DA (1996) Structure of the female reproductive tract in the Dungeness Crab (Cancer magister) and implications for the mating system. Biol Bull 190:336-349

Jivoff PR (1997) The relative roles of predation and sperm competition on the duration of the post-copulatory association between the sexes in the blue crab, Callinectes sapidus. Behav Ecol Sociobiol 40:175-185

Jivoff PR, Hines AH, Quackenbush S (2007) Reproduction biology and embryonic development. In: Kennedy VS, Cronin LE (eds) The blue crab, Callinectes sapidus. Maryland Sea Grant, College Park, MD, p 255-298

Kendall MS, Wolcott DL, Wolcott TG, Hines AH (2001) Reproductive potential of individual male blue crabs, Callinectes sapidus, in a fished population: depletion and recovery of sperm number and seminal fluid. Can J Fish Aquat Sci 58:1168-1177

Kendall MS, Wolcott DL, Wolcott TG, Hines AH (2002) Influence of male size and mating history on sperm content of ejaculates of the blue crab Callinectes sapidus. Mar Ecol Prog Ser 230:235-240

McLay CL, López Greco LS (2011) A hypothesis about the origin of sperm storage in the Eubrachyura, the effects of seminal receptacle structure on mating strategies and the evolution of crab diversity: How did a race to be first become a race to be last? Zool Anz 250:378-406

Oh SJ, Hankin DG (2004) The sperm plug is a reliable indicator of mating success in female Dungeness crab, Cancer magister. J Crustac Biol 24:314-326

Pitnick S (1993) Operational sex ratios and sperm limitation in populations of Drosophila pachea. Behav Ecol Sociobiol 33:383-391

Sainte-Marie B (1993) Reproductive cycle and fecundity of primiparous and multiparous female snow crab, Chionoecetes opilio, in the northwest Gulf of Saint Lawrence. Can J Fish Aquat Sci 50:2147-2156

Sainte-Marie B (2007) Sperm demand and allocation in decapod crustaceans. In: Duffy EJ, Thiel M (eds) Evolutionary ecology of social and sexual systems: crustaceans as model organisms. Oxford University Press, New York, NY, p 191- 209

Sainte-Marie B, Hazel F (1992) Moulting and mating of snow crabs, Chionoecetes opilio (O. Fabricius), in shallow waters of the northwestern Gulf of Saint Lawrence. Can J Fish Aquat Sci 49:1282-1293 
Sainte-Marie B, Lovrich GA (1994) Delivery and storage of sperm at first mating of female Chionoecetes opilio (Brachyura: Majidae) in relation to size and morphometric maturity of male parent. J Crustac Biol 14:508-521

Sainte-Marie B, Sévigny JM, Carpentier M (2002) Interannual variability of sperm reserves and fecundity of primiparous females of the snow crab (Chionoecetes opilio) in relation to sex ratio. Can J Fish Aquat Sci 59: 1932-1940

Sato T, Goshima S (2006) Impacts of male-only fishing and sperm limitation in manipulated populations of an unfished crab, Hapalogaster dentate. Mar Ecol Prog Ser 313:193-204

Sato T, Ashidate M, Jinbo T, Goshima S (2006) Variation of sperm allocation with male size and recovery rate of sperm numbers in spiny king crab Paralithodes brevipes. Mar Ecol Prog Ser 312:189-199

Sato T, Ashidate M, Jinbo T, Goshima S (2007) Does maleonly fishing influence reproductive success of the female spiny king crab, Paralithodes brevipes? Can J Fish Aquat Sci 64:735-742

Sato T, Yoseda K, Okuzawa K, Suzuki N (2010) Sperm limitation: possible impacts of large male-selective harvesting on reproduction of the coconut crab Birgus latro. Aquat Biol 10:23-32

Song HT, Ding YP, Xu YJ (1988) A study on the breeding habits of blue crab (Portunus trituberculatus) in the northern coastal waters of Zhejiang. J Zhejiang Coll Fish 7:39-46

Sun YM, Song ZL, Yan RS, Gong MJ, Sun JJ (1984) Preliminary study on the growth of Portunus trituberculatus. Acta Ecol Sin 4:57-64

Wedell N, Gage MJG, Parker GA (2002) Sperm competition,

Editorial responsibility: Bernard Sainte-Marie,

Mont-Joli, Quebec, Canada male prudence and sperm limited females. Trends Ecol Evol 17:313-320

Wolcott DL, Hopkins CWB, Wolcott TG (2005) Early events in seminal fluid and sperm storage in the female blue crab Callinectes sapidus Rathbun: effects of male mating history, male size, and season. J Exp Mar Biol Ecol 319: $43-55$

Wu XG, Yao GG, Yang XZ, Cheng YX, Wang CL (2007) A study on the ovarian development of Portunus trituberculatus in East China Sea during the first reproductive cycle. Acta Oceanol Sin 29:120-127

Xuan FJ, Guan WB, Dai XJ, Zhu JF (2009) Structure and content of spermathecae of Portunus trituberculatus from East China Sea. Chin J Zool 44:1-11

Xue JZ, Du NS, Lai W (1997) A review of studies on Portunus trituberculatus in China. Donghai Mar Sci 15:60-65

Yu CG, Song HT, Yao GZ, Shen XY (2003) Study on rational utilization of crab resources in the inshore water of Zhejiang. Mar Fish 25:136-141

Yu CG, Song HT, Yao GZ (2004) Assessment of the crab stock biomass in the continental shelf waters of the East China Sea. J Fish China 28:41-46

Yu CG, Song HT, Yao GZ, Lu HQ (2006) Composition and distribution of economic crab species in the East China Sea. Oceanol Limnol Sin 37:53-60

Zhaung ZM, Deng J (1999) Overview on the crustaceans in the Chinese waters of the PICES Region. Fourth meeting of PICES Working Group 12, Yellow Seas Fisheries Research Institute, Qingdao

Zhen YJ, Chen XZ, Chen JH (2003) The biological resources and environment in continental shelf of the East China Sea. Shanghai Science \& Technology Press, Shanghai, p 30-375

Submitted: July 3, 2013; Accepted: December 20, 2013

Proofs received from author(s): March 18, 2014 